\title{
Lube Oil Consumption Simulation: Validation ANd Parametric INVESTIGATION
}

\author{
Marcos Manoel Valverde Pereira ${ }^{1}$, Pedro Vitor Bacchin ${ }^{1}$, Walter Zottin ${ }^{1}$ \\ ${ }^{1}$ MAHLE Metal Leve S/A, Virtual Engine Development \\ E-mails: marcos.pereira@br.mahle.com, pedro.bacchin@br.mahle.com, \\ walter.zottin@br.mahle.com
}

\begin{abstract}
In order to better understand and control the engine lube oil consumption (LOC) during the engine development process, manufacturers request quantitative LOC estimations by numerical simulation.

This paper presents a study performed by MAHLE Metal Leve simulation team, in order to explore the level of confidence and reliability of available commercial LOC simulation codes. An initial validation using engine test results was carried-out and some parametric studies were performed to estimate the influence of some model variables on LOC.

One code was selected considering aspects like: levels of development and complexity, technical support and correlation with the measurements results. This selected code is already available at MAHLE Metal Leve helping to better predict and understand the LOC causes. It is supporting the exploration of engine components optimization to reduce engine LOC in combination with several other demands like friction, durability etc.
\end{abstract}

\section{INTRODUCTION}

Nowadays, due to the engine loads increase and the demand for more efficient and environmental friendly engines, manufacturers are concentrating efforts to optimize engines lubrication in order to reduce parts wear, engine emissions and minimize power losses by friction. The engine oil performance can influence the Power Cylinder Unit (PCU) emissions, friction and thus the fuel consumption [1].

Furthermore, due to the release of new emission standards, as example in Brazil, the Proconve P-7 from CONAMA [2], the concern regarding emissions from engines increased, as part of it, the lube oil consumption. Unburned or partially burned oil in the exhaust gases directly contributes to hydrocarbon and particulate emissions [3,4] and also poison the exhaust gas treatment devices severely reducing their conversion efficiency [5, 6]. Therefore, as a compromise solution, the LOC may be reduced but keeping friction and wear in an acceptable level.

Mainly some customers in the South American market want to have quantitative data for LOC. Thus we benchmark available tools for their performance in this direction from time to 
time. Based on literature review and market analysis, some potential LOC calculation codes [7] were identified. During a validation phase, the AVL Excite code presented good adherent results correlation and we received good software support. The code reached a good blowby and ring dynamics behavior correlations with results generated by the global MAHLE MIT simulation models, which are developed in more than a decade in a research consortium at the Massachusetts Institute of Technology in Boston, USA.

In order to achieve this targeted LOC level during the engine development process, it is desirable to have a reliable LOC estimation to be used in the qualitative sense, generating direct trends and directions regarding LOC [8]. Such an approach brought reasonable improvements for a new engine [9].

\section{SOFTWARE VALIDATION}

The most difficult and tricky part of the simulation is the model generation with it's calibration phase, not because of the modeling itself, but mainly by not having measurement values, once is quite difficult to measure or estimate the contribution of each LOC mechanism.

Basically four different LOC sources (see figure 1) are known and used:

Evaporation: It is a portion of the oil adherent to the cylinder inner surface that is evaporated by the high gas temperature;

Throw-off: It is the amount of oil above top ring, which is exposed to the acceleration forces. The amount of oil above top ring is the sum of the oil scrapped by the top ring and the oil that flows at the side faces of top ring (oil pumping);

Blow-back Sometimes, during the engine cycle, a reverse gas mass flow from the ring pack to the combustion chamber can occur. When it happens, some oil particles can be dragged together and may be burned or gone away through the valves;

Oil Piston Scraping: It is a portion of the oil scraped by the piston top land's edge (also considering deposits at top land).

The proportions of these mechanisms are difficult to estimate or even to measure them in a running engine.
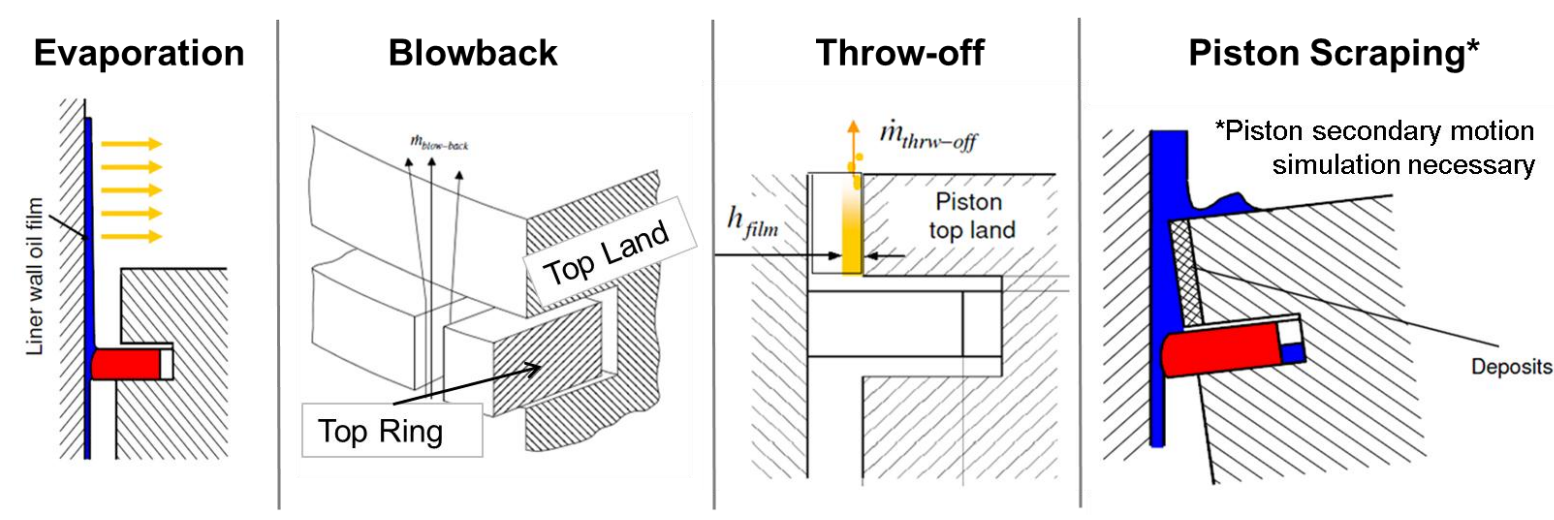

Figure 1 - Lube Oil Mechanisms details 
For AVL Code validation an 8.9L Diesel engine at rated power condition was simulated. This engine was selected for this validation because it was previously exhaustively simulated inside MAHLE, using the MIT models for ring dynamics simulation. So, besides the LOC and Blowby measured results, some dynamics simulation results are also available for comparison.

The 8.9L Diesel engine was bench tested and simulated considering two different piston and ring pack designs. So it was possible to calibrate the model and test the model correlation for defined design modifications. Figure 2 presents the blowby comparison (measured values vs MIT simulated results vs AVL Excite simulated results). The LOC comparison is shown as well, but in this case only measured versus AVL simulated values, as MIT models present up to now only indirect and qualitative results in terms of LOC. The total values are comparable. The proportion of the different fractions is assumed to achieve the calibration data set. That is one of the reasons why we still use qualitative comparable results as long as we do not have the physics behind the effects fully described and included.

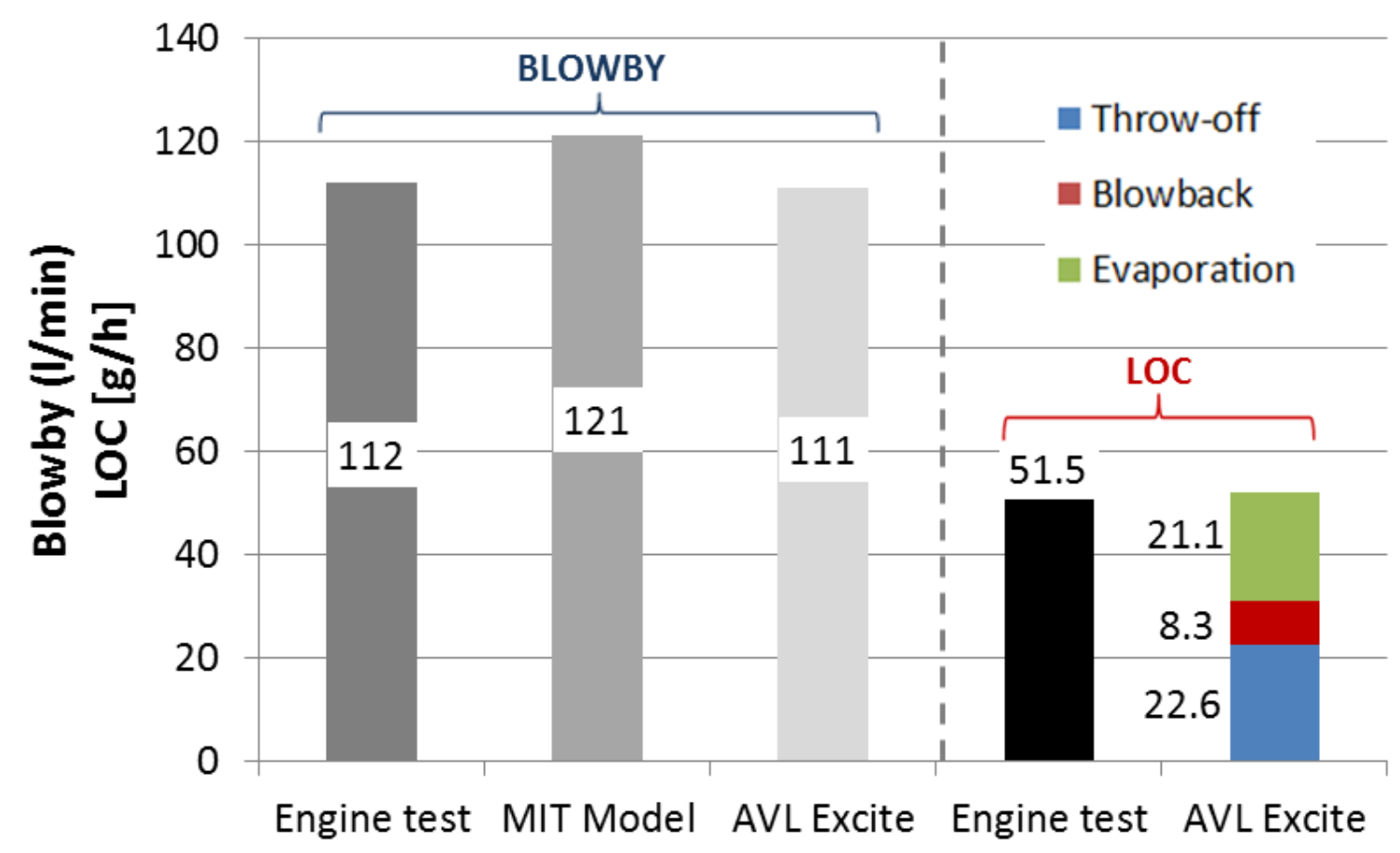

Figure 2 - Blowby and LOC simulation results, comparing Measured, MIT and AVL Excite values

It is known that geometrical parameters in the PCU can influence the engine Blow-by and LOC $[8,9,10,11]$. Considering this, the 2 different piston and rings sets mentioned before would be modeled to analyze if the code was able to reproduce each set of engine tests LOC results trends and therefore determine if the code presents acceptable correlation for LOC estimation in absolute values. For that, all the calibrated parameters in the model were frozen, only changing, when necessary, the component's geometric dimensions for the proposed PCU. 


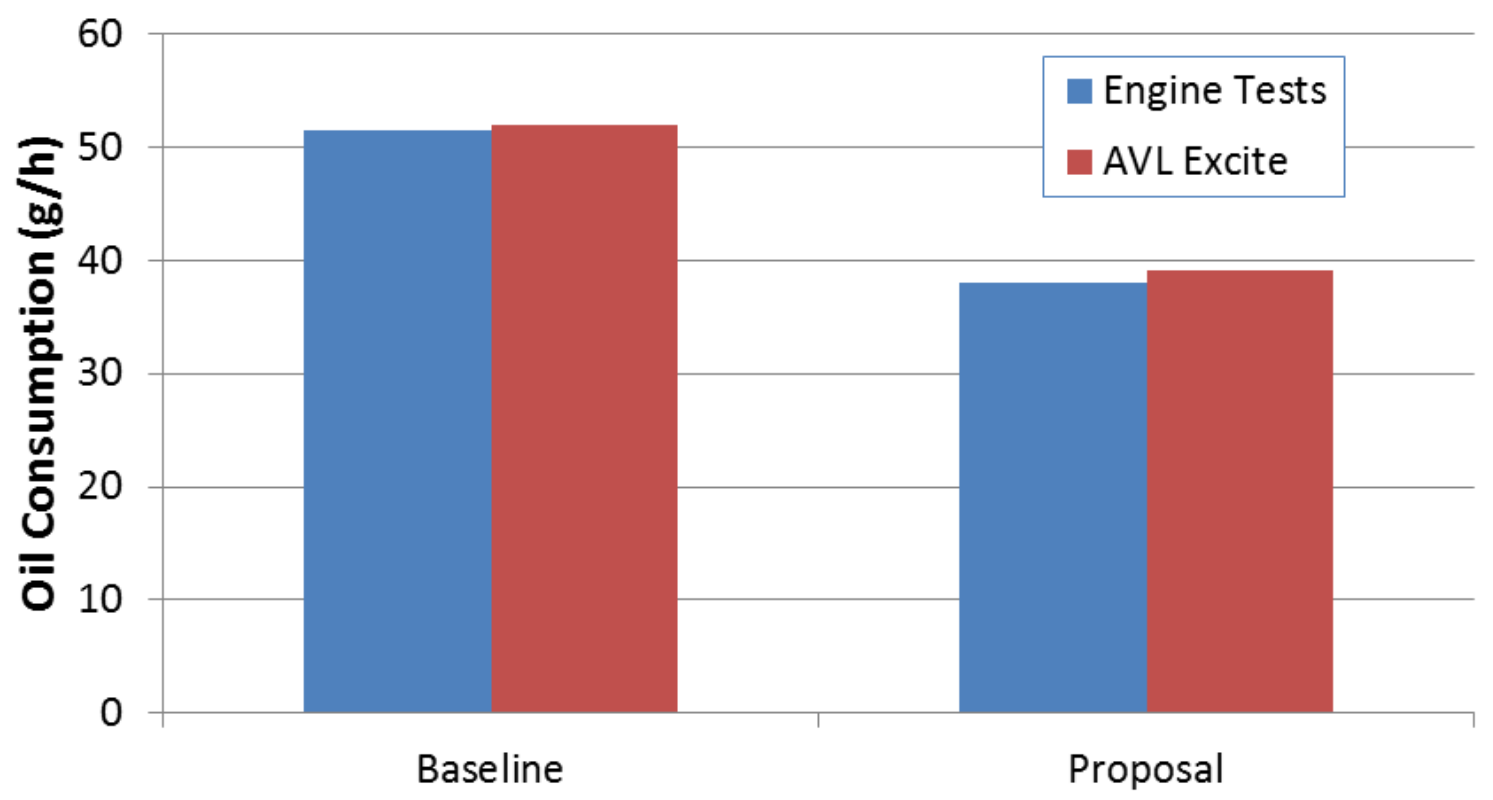

Figure 3 - LOC correlation between measured and AVL Excite simulation results changing the PCU

Figure 3 presents correlation results for Rated Power condition as an example of correlation level obtained during this benchmarking phase. It is important to remark that the correlation levels may be influenced by different parameters (e.g.: components dimensions, thermal deformation and temperatures, simulation environment definition, etc.) but it is also positively affected by the expertise of the user and learning curve.

Some problems to achieve an acceptable correlation between AVL Excite and measured values were observed mainly for low load conditions and are under evaluation. For now, it is recommended to use the software for loads near the maximum, mainly for higher speeds, while further validation studies for low loads are under progress.

\section{CASE STUDIES}

To demonstrate some of the software potential uses, selected simulated cases are summarized and listed in this paper. The presentation of these cases explores the software capabilities to indicate possible causes of the LOC and simulate different solutions in order to achieve, if possible, the best compromise considering LOC and the other engine performance parameters, like blowby and friction.

One of the direct applications of the AVL Excite code is the simulation of alternative proposals for LOC reduction. It is possible and beneficial to integrate the simulation techniques to the technical expertise to improve the confidence level and to guarantee an improved solution in terms of engine component design. In this integration, the technical expertise role is to propose solutions for simulation and assure that these solutions are feasible. The role of the simulation techniques is to simulate the trivial and, if necessary, the non-trivial solutions presenting the expected effect of each proposal [12].

2.1. Piston and Ring Pack Modifications and Their Effect on LOC 
Figure 4 presents an example of the proposed simulation approach, simulating different PCU's (Piston and ring) designs using a HSD engine type as reference. First, the reference model (Baseline PCU) is calibrated using measured results. Then an intuitive (based on technical expertise) PCU design alternative is simulated. If necessary, some potential solutions (non-intuitive) are simulated in order to find additional benefits. In some cases it is also possible to use an optimization module to improve the results (this is not the case in this paper).

In this way, in Figure 4 it is possible to observe an improvement between Baseline PCU and the Preliminary PCU. After some additional investigations, the "Premium" alternatives presented a stronger reduction in the LOC, mainly in the Blowback mechanism. In this case the variations in the other LOC mechanisms arealmost not affected by the PCU design optimization or the code cannot differentiate it.

It is also important to remark that this simulation results are only for a specific engine condition, so in most cases the intuitive (preliminary) PCU alternative will present better results than the reference PCU. In all cases, it is recommended to evaluate several other engine conditions to assure that the proposed modifications do not jeopardize engine performance but the results are still within acceptable levels.

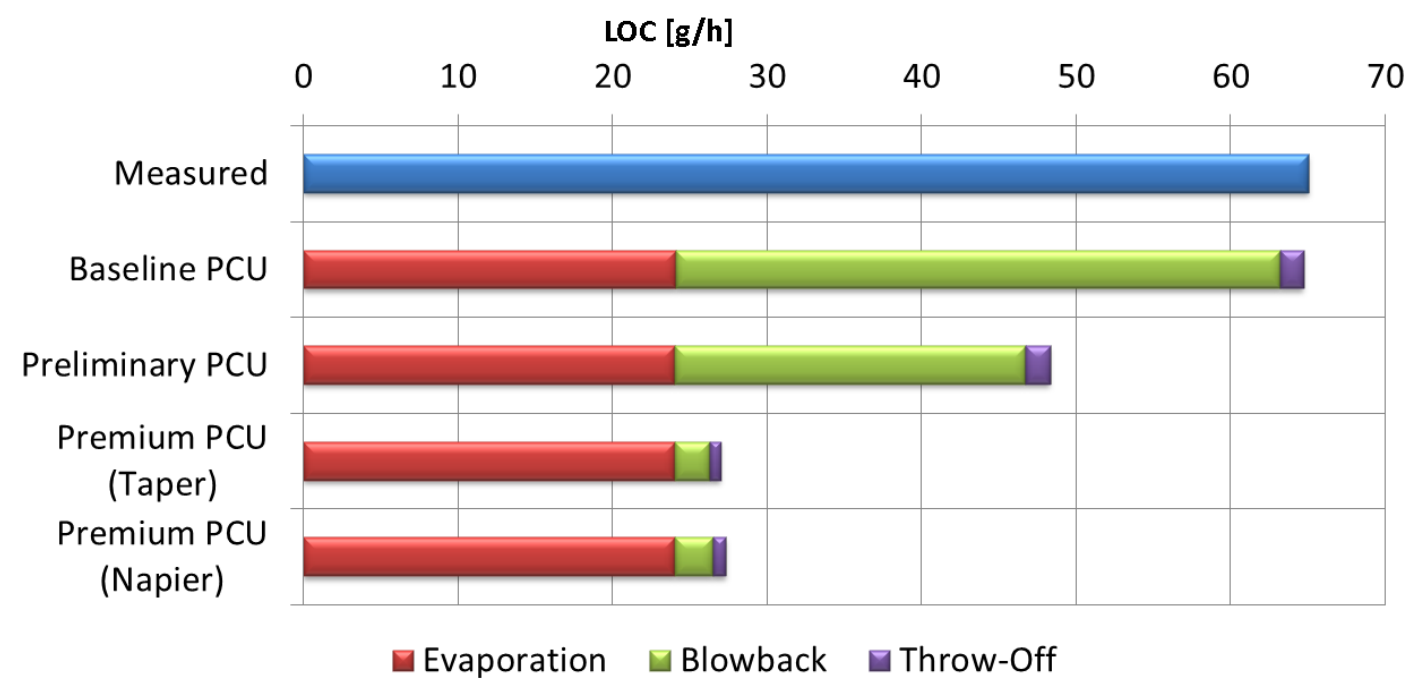

Figure 4 - Simulation LOC results of PCU design proposals - reference engine HSD type

\subsection{Cylinder Inner Surface Roughness Sensitivity Study}

Cylinder inner surface topology and its iteration with piston and especially with rings surfaces are very important for LOC. Many different honing processes were developed in order to reduce friction and wear in contact area between cylinder inner surface and ring or piston skirt regions [13,14]. Again, a compromise solution must be achieved in order to reduce LOC and keep friction and wear in an acceptable level.

Figure 5 presents the $\mathrm{Rq}$ roughness variation effect on the LOC, for a HSD engine, for the same PCU alternatives presented in item 2.1 of this paper. It is possible to observe a LOC reduction with roughness reduction, until a certain level, where the 
LOC keeps almost constant and independent from roughness variation. This tendency also is one of the explanations of the run-in effect on LOC, where usually the LOC tends to decrease with engine running time, mainly in the initial hours.

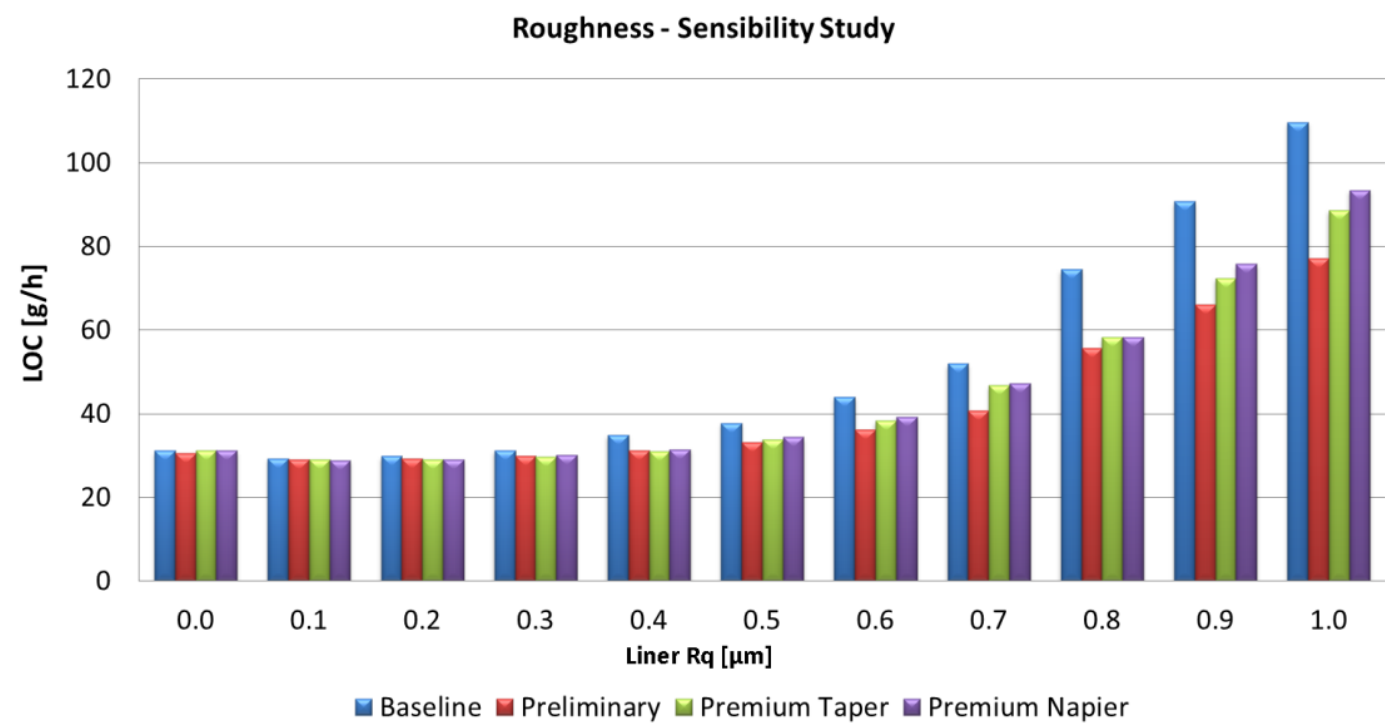

Figure 5 - Cylinder Inner Surface Roughness effect on LOC - engine HSD

\subsection{Cylinder Thermal Effect on LOC}

Different cylinder inner surface deformations and temperatures are also responsible for LOC variations. These deformations and temperatures are mainly dependent on cylinder material, cooling systems and engine block configuration.

A case where cylinder liner material of a HDD engine was modified and an increase of the LOC happened was simulated in order to understand the reasons of this LOC increase. Figure 6 presents the following simulation results: Case 01 - the new liner using its resultant new temperature (higher than the baseline liner) and deformation; Case 02 - the baseline liner simulated using its temperature and deformation; Case 03 - the new liner using its deformation but the temperature from the baseline liner; and, Case 04 - the baseline liner using its deformation but the temperature from the new liner. See table 1.

Table 1 - Bore Deformation and Temperatures simulated cases

\begin{tabular}{|l|c|c|}
\hline & Bore Deformation & Bore Temperature \\
\hline Case 01 & New & New \\
\hline Case 02 & Baseline & Baseline \\
\hline Case 03 & New & Baseline \\
\hline Case 04 & Baseline & New \\
\hline
\end{tabular}




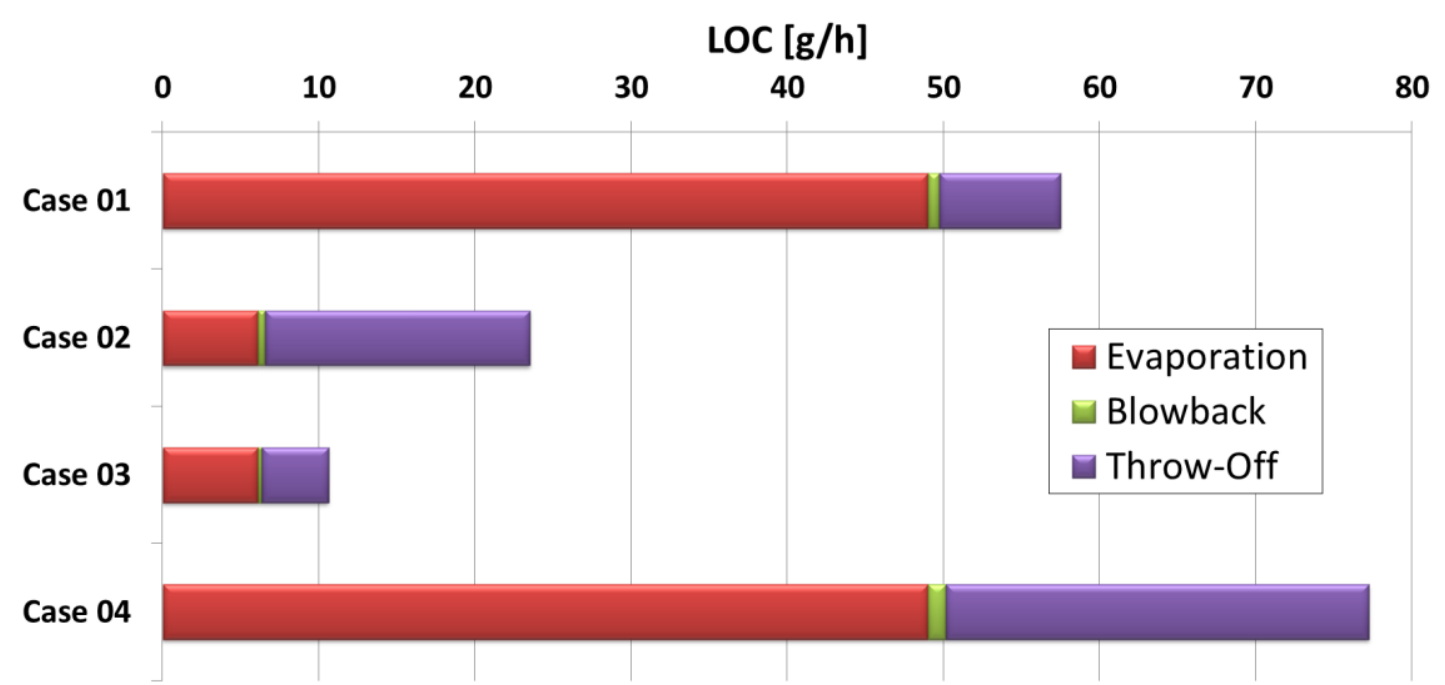

Figure 6 - Cylinder bore deformation and temperature effect in the LOC - engine HDD

Evaluating all results it is possible to conclude that the new liner compared to the previous liner increased LOC because evaporation portion was increased (even presenting Throw-off reduction). The liner temperature presents a large impact on the LOC, by reducing the evaporation; this is confirmed by changing the temperatures of the liners and simulating again the same models, as shown in figure 6 .

To reinforce the importance of the cylinder temperature in the LOC, a parametric study was made keeping constant the bore deformation, only changing the cylinder temperature for a HDD engine. Figure 7 presents the liner temperature influence in all LOC mechanisms.

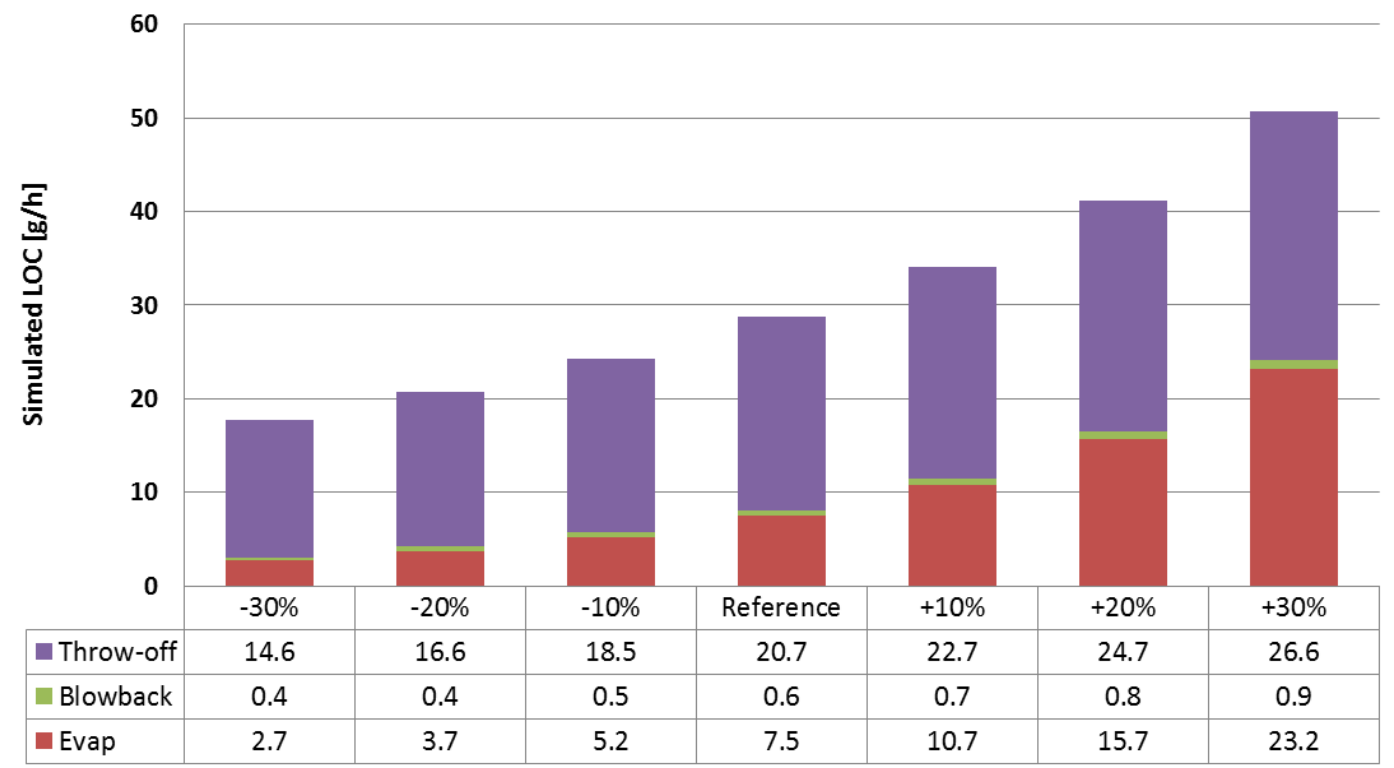

Figure 7 - LOC variation due to engine cylinder temperature variation

2.4. Effect of Oil Control Ring Tangential Force on LOC - HSD Engine

One other relevant influenece for LOC is the Oil Control Ring (OCR). Some design characteristics as OCR type and material or contact face profile are fundamental. 
However once these characteristics are selected, the tangential force $(\mathrm{Ft})$ is the governing parameter in terms of LOC performance. Figure 8 presents an example of the effect of the OCR Ft. The OCR Ft effect on the LOC is important not only with the nominal value, but also with the tolerance definition. In this way, it is also possible to simulate the effect that running hours by wearing out the OCR form and as a consequence have expander relaxation.

In the case presented in the figure 8 , it is possible to observe an increase in the LOC Throw-off mechanism when the OCR Ft is lower than $45 \mathrm{~N}$, for OCR Ft larger than $45 \mathrm{~N}$ the LOC mechanisms are almost constant. It is also possible to observe that, in this case, the other LOC mechanisms are barely impacted by OCR Ft, if the code can already dissolve these details correctly.

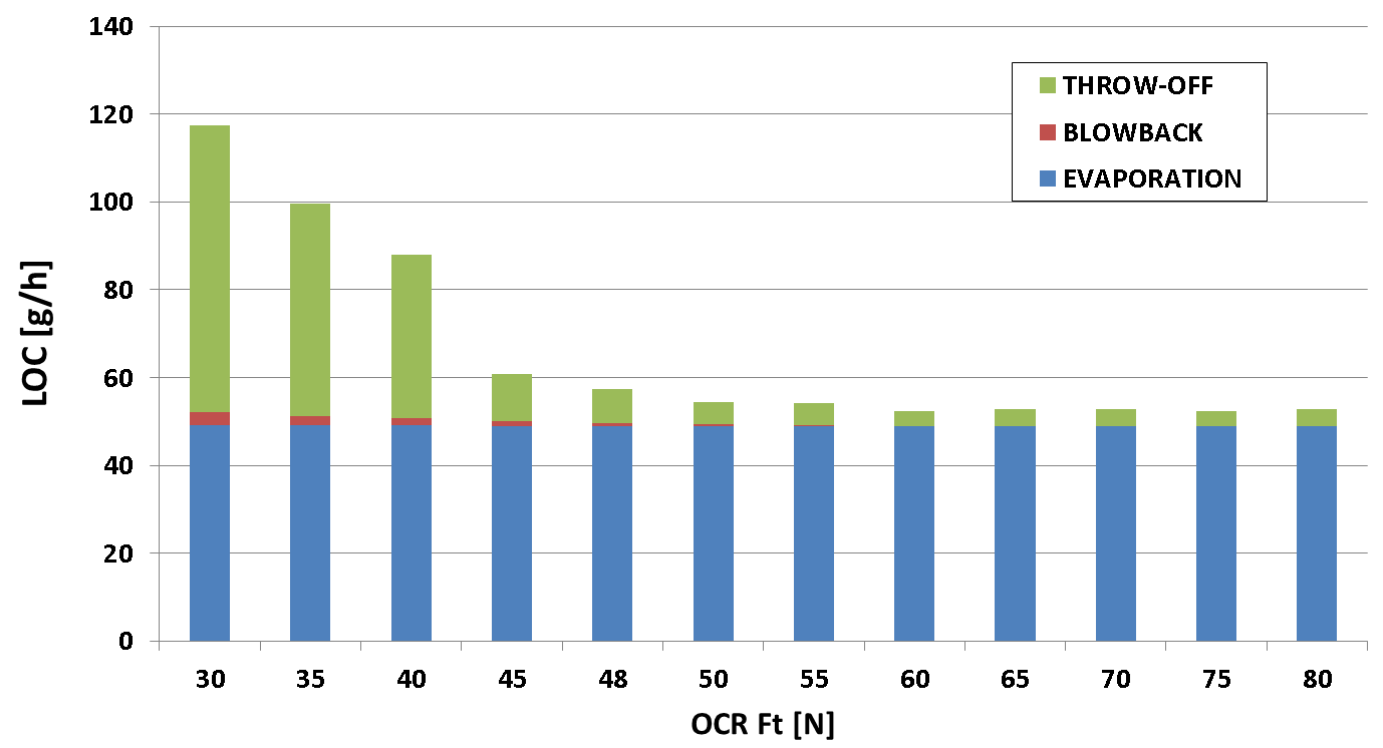

Figure 8 - OCR Tangential Force effect on the Oil Consumption - HSD engine

\subsection{Ring contact face wear}

Another interesting feature in the software is the ring face wear prediction and iterative update of the contact face in the model, allowing the simulation of a progressive wear effect on ring dynamics, including on LOC and Blowby [11]. This feature allows a simulation of the engine running time (or the number of engine cycles) and the expected ring dynamics variation due progressing ring face wear. The correlation between engine mileage and cycles is not linear and may vary from engine to engine. Figures 9 and 10 present respectively the simulated top ring wear and the resultant LOC and Blowby variation for a gasoline engine.

In the figure 9 it is presented the top ring face wear progression. Each line represents the worn contact face after a certain amount of cycles. It is possible to accelerate the wear progression, but the drawback is the tendency of excessive (and incorrect) localized wear. 


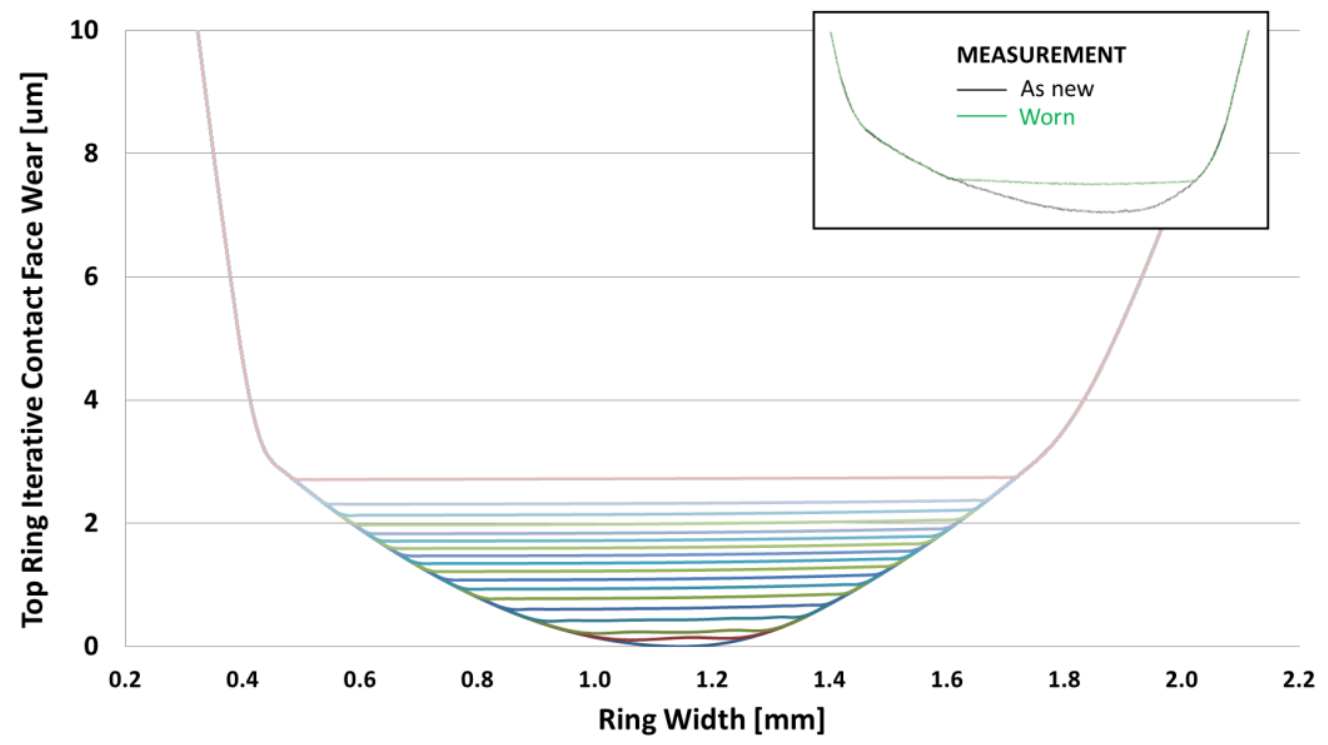

Figure 9 - Top ring contact face iterative wear progression - Gasoline engine

In the figure 10, it is possible to observe the face wear effect on the simulated LOC and Blowby. The AVL Excite simulates the model using the current contact face, calculate the LOC, Blowby and the worn contact face. After that, the software substitute the contact face by the new worn contact face and redo the simulation, calculating again the LOC, Blowby and the contact face wear. So this interaction continues until the wear amount (or other defined boundary condition, like blowby or LOC spikes) reaches a certain level. The observed trends for LOC (decrease after an initial running phase) and for Blowby (increase because the top ring gap increase, caused by the contact face wear) are quite often observed on similar Gasoline engines.

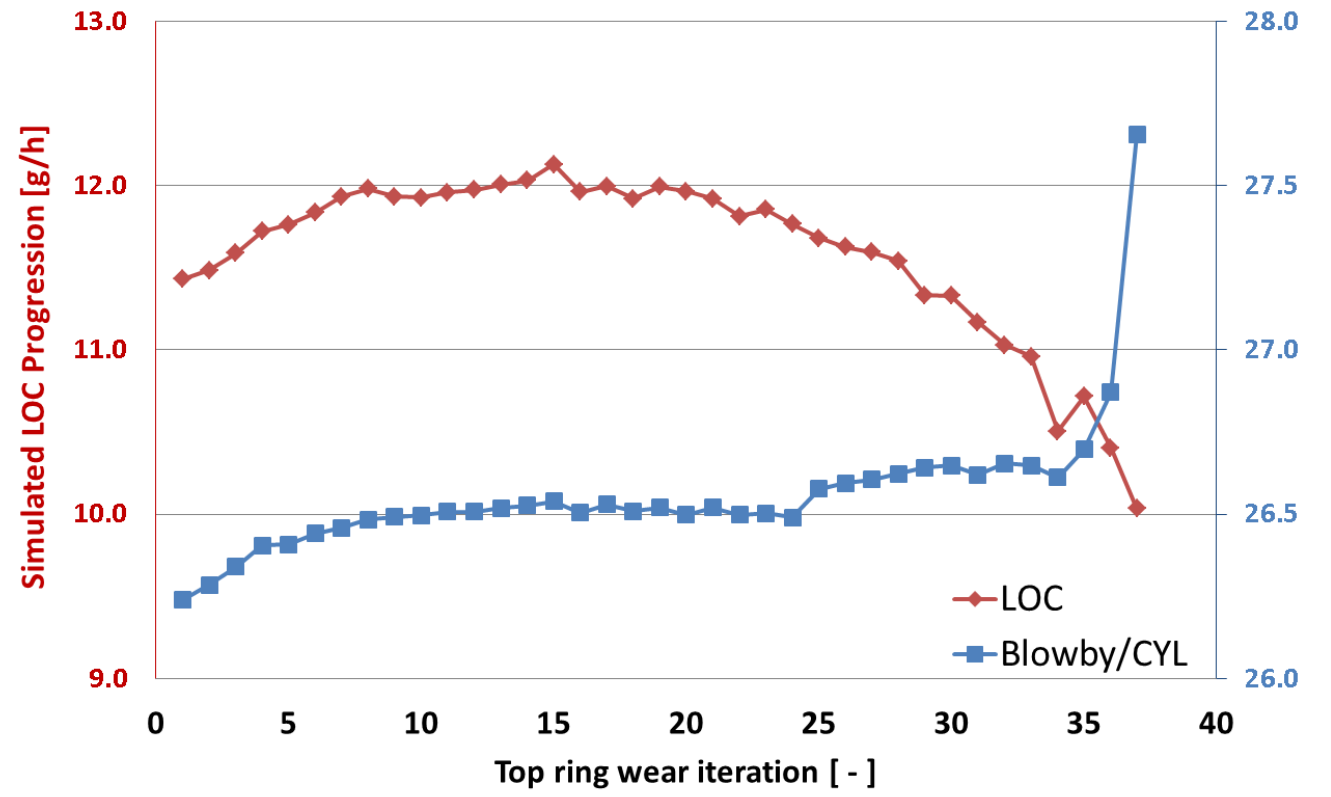

Figure 10 - Simulated LOC and Blowby evolution due to top ring wear - Gasoline engine 
This type of simulation is still under development and is presented as a demonstration of potential future use. It depends on engine test results to calibrate the number of iterations and the wear accumulated over engine test hours. The relation between interactions and engine test time is expected to vary from engine to engine and even for test cycle loads. That is why absolute data in $\mathrm{g} / \mathrm{h}$ per engine and furthermore per cylinder in an engine might lack of accuracy in prediction.

\section{CONCLUSIONS}

In this paper it was summarized the validation and some actual simulation cases demonstrating potential applications of the LOC simulation procedure inside MAHLE Metal Leve for engine LOC evaluation and when necessary the effect of proposed PCU modifications on it.

One of the most interesting features of the LOC simulation procedure is the calculation of different LOC mechanisms values, allowing a better evaluation of the LOC causes and if necessary, the selection and simulation of precise and delimited proposals or in some cases explore non-trivial proposals.

It was shown the influence of: PCU design (piston and ring), cylinder bore roughness; cylinder bore temperature and deformation, top ring face wear and OCR tangential force, on LOC. Such approach can not be considered a general rule once it is directly affected by the boundary conditions. A significant knowledge on engine and component systems is the key factor to enable a complete and reliable prediction of effects and research is on going to have more reliable quantitative data in future.

\section{Contact information:}

Marcos Manoel Valverde Pereira

MAHLE Metal Leve S.A. - Virtual Engine Development

Rodovia Anhanguera, sentido interior - capital, km 49,7 - Bairro Tijuco Preto

Jundiaí - SP - 13210-877

Tel.: (011) 4589-0650

E-Mail: marcos.pereira@br.mahle.com

Definitions/Abbreviations

HDD - Heavy Duty Diesel

HSD - High Speed Diesel

LOC - Lube Oil Consumption

PCU - Power Cylinder Unit

\section{REFERENCES}

[1] Tseregounis, S., McMillan, M., and Olree, R., "Engine Oil Effects on Fuel Economy in GM Vehicles - Separation of Viscosity and Friction Modifier Effects," SAE Paper 982502, 1998

[2] CONAMA “Conselho Nacional do Meio Ambiente”, Resolution No. - 403, Federal Official Gazette - Section 1 No. 220, Brazil, November 11th, 2008. 
[3] Heywood, J. B., "Internal Combustion Engine Fundamentals", McGraw-Hill, 1988. [4] Mayer, W. J., Lechman, D. C., and Hilden, D. L.: "The Contribution of Engine Oil to Diesel Exhaust Particulate Emissions," SAE paper 800256, 1980.

[5] Drury, C., and Withehouse, S.: "The Effect of Lubricant Phosphorus Level on Exhaust Emissions in a Field Trial of Gasoline Engine Vehicles," SAE paper 940233, 1994.

[6] Ueda, F., Sugiyama, S., Arimura, K., Hamaguchi, S., and Akiyama, K.: "Engine additive Effects on Deactivation of Monolithic Three-Way Catalysts and Oxygen Sensors," SAE paper 940746, 1994.

[7] Bacchin, P. V., Zottin, W., Pereira, M., "Benchmark About LOC Calculation.”, MAHLE Internal Report RMSN12/0362-63, 2012

[8] Zottin, W., Clemente, M., and Leite M.M. "Predictive Analysis of Lube Oil Consumption for a Diesel Engine," SAE Paper 950520, 1995

[9] Zottin, W., Bacchin, P. and Garcia, A., "Numerical Simulation Study of Carbon Build-up and Oil Consumption in a Heavy Duty Diesel Engine," SAE Int. J. Engines 5(3):2012, doi: 10.4271/2012-01-1326.

[10] Zottin, W., Clemente, M., and Villar C.A. "Heavy Duty Diesel Engine Lube Oil

Consumption Simulation and Correlation with Engine Tests," ASME Fall ICE Meeting, 2000

[11] Tian, T., Rabute, R., Wong, V. W., and Heywood, J. B., "Effects of Piston-Ring Dynamics on Ring/Groove Wear and Oil Consumption." SAE Paper 970835

[12] Pereira, M., Zottin, W.: "Optimization process and robustness calculation for engine components - ring pack study case" SAE Paper 2009-36-0069, 2009.

[13] Hill, S. H., Brown, J. R., Hamelink, J. C., 1995, “An Experimental Study of the Effect of Cylinder Bore Finish on Engine Oil Consumption”, SAE paper 950938.

[14] Hill, S. H., 2001, "Cylinder Bore Finishes and their Effect on Oil Consumption", SAE paper 2001-01-3550. 